\title{
Competitive Removal of Heavy Metal Ions from Squid Oil under Isothermal Condition by CR11-Chelate Ion Exchanger
}

Omid Tavakoli ${ }^{1}$, Vahabodin Goodarzi ${ }^{2}$, Mohammad Reza Saeb $^{3}$, Niyaz Mohammad Mahmoodi $^{4}$, Rafael Borja ${ }^{5}$

${ }^{1}$ School of Chemical Engineering, College of Engineering, University of Tehran (UT), Tehran, Iran

${ }^{2}$ Applied Biotechnology Research Center, Baqiyatallah University of Medical Sciences, P.O. Box 19945-546, Tehran, Iran

${ }^{3}$ Department of Resins and Additives, Institute for Color Science and Technology, P. O.Box: 16765-654, Tehran, Iran

${ }^{4}$ Department of Environmental Research, Institute for Color Science and Technology, Tehran 1668814811, Iran

${ }^{5}$ Instituto de la Grasa (CSIC), Campus Universidad Pablo de Olavide, building 46, Ctra. de Utrera km 1, 41013-Sevilla, Spain

To whom correspondence should be addressed:

Dr. Omid Tavakoli: E-mail: otavakoli@ut.ac.ir 


\section{ABSTRACT}

Heavy metal ions $\left(\mathrm{Cu}^{2+}, \mathrm{Pb}^{2+}, \mathrm{Cd}^{2+}\right.$ and $\left.\mathrm{Zn}^{2+}\right)$ are serious threats to the environment. Squid belongs to shellfish family and can be found in the bottom sediment. The present work serves sub-critical water treatment to mimic contamination of squid oil when it hydrolyzes into a three-phase solution composed of aqueous, metal-soap and oil layers. Isothermal adsorption of metal ions was studied to visualize competitive chelation from aqueous phase to oil phase (493, 523,548 , and $573 \mathrm{~K}$ ) for solutions possessing dissimilar initial concentration of metal ions. The decomposition of glycerides into fatty acids was favored at an elevated subcritical temperature, where metal-soap phase revealed the highest chelation ability toward $\mathrm{Cu}^{2+}$ ion $(96 \%$ at above $500 \mathrm{~K}$ ). To evaluate the possibility and the extent of oil recovery, removal of heavy metal ions from contaminated oil was performed by CR11 chelate ion exchanger. The superiority of CR11 in trapping metal ions was featured by comparing its performance as sorbent with commonly used PEI-chitosan beads and PEI-chitosan fiber sorbents. It was found that CR11 chelate ion exchanger facilitates removal of ions from metal-soap and oil phases obtained at low temperatures, where $\mathrm{Zn}^{2+}$ and $\mathrm{Cd}^{2+}$ could be separated easier compared to $\mathrm{Cu}^{2+}$ and $\mathrm{Pb}^{2+}$.

Keywords: Squid Oil; Adsorption Isotherm; Chelate Ion Exchanger; Subcritical Water Treatment; Heavy metal ions 


\section{Introduction}

The heavy metal ions such as $\mathrm{Cu}^{2+}, \mathrm{Pb}^{2+}, \mathrm{Cd}^{2+}$ and $\mathrm{Zn}^{2+}$ are the main threats to the natural sources of creatures [1-4]. The transmission of heavy metal ions from one living being to the other(s) leads to serious contamination of aqueous environment [5]. The progress in urbanization, especially coastal cities lends itself to contamination of water sources with heavy metal ions, which are easily entered into the aqueous media [6]. Such contaminants directly diffuse into the bodies of phytoplanktons, zooplanktons, the bacteria and marine organisms causing contamination of food chains [7-8]. As a consequence of this, marine products and wastes pose high risks for the human life. For instance, 1.3 million tons of marine wastes are generated every year only in Japan, which brings about diverse consequences to the environment. According to the London Agreement, discharge of wastes into the sea is illegal [9]. Therefore, diverse routes have been developed over the last years to diminish the content of or idealistically complete removal of heavy metal ions and organic pollutants from the effluents, including chemical precipitation, ion exchange reactions, electrodialysis, reverse osmosis, and adsorption of ions by low-cost adsorbents like activated carbons [10-14]. On the other hand, incineration of marine wastes appears as an easy route which has been implemented over the past decades in the undeveloped/under developing countries. The burning, however, brings serious disadvantages of air pollution and transmission of 
heavy metal ions into the air, which itself creates more issues to the health of living organisms [15-16].

Reports show that there are large amounts of fat and oil in the marine wastes. This strengthens the idea that rich food sources are potentially available to recover. It was confirmed that sub-critical water treatment can be considered as a green economical method to convert marine wastes to value-added materials [17-18]. It was previously demonstrated that amino, fatty, and organic acids can be produced from waste squid entrails using sub-critical water hydrolysis. According to the literature, 100 tons marine wastes in the step I ( $479 \mathrm{~K}, 5 \mathrm{~min})$ can gain 0.29 and 4.5 tons of alanine and soluble proteins, respectively; while in the step II $(513 \mathrm{~K}, 50 \mathrm{~min})$ from the solid obtained from the first step one can achieve 0.27 and 0.15 tons of amino acids and organic acids, respectively [19]. Elsewhere valued materials are obtained from scallop viscera, implying that transesterification taking place during sub-critical treatment plays an important role in production of fatty acids from organic wastes, so that from $100 \mathrm{~g}$ marine waste $(473 \mathrm{~K}, 10 \mathrm{~min})$ one can obtain $0.61,1.03$, and 7.9 grams of eicosapentaenoic acid (EPA), docosahexaenoic acid (DHA), and fatty acid methyl esters (FAMEs), respectively [20-21].

Procurement of edible or eco-friendly fatty acids from the marine wastes seems to be a prodigious output. Marine wastes are rich in omega-3 fatty acids and FAMEs, and due 
to their similar physical properties to diesel fuel can be applied in production of biofuel [22-24]. The presence of heavy metal ions in the marine wastes, however, necessitates their cleanup before usage. The tissues in which such ions are normally deposited are digestive gland and kidney [25]. Fatty acids of type FAMEs are the most potent ones that may enter the aforementioned organs; hence, they are a main source for pollutants. The continued works of this group on sub-critical removal of heavy metal ions from squid and scallop wastes have shown that three phases are formed in which heavy metal ions are distributed [26-27]. Metal-soap and oil phase contain the major proportion of metal ions with chelate agent from squid wastes. In parallel, many studies have focused on application of sub-critical method for clean production from marine wastes [28-30]. In this sense, application of synthetic resins for chelating metal ions was considered as a promising solution [31-32]. Such exchange resins are versatile in diverse fields ranging from purification of industrial wastes to ion exchange membranes [33-35]. It was accepted that chelating resins are suitable for selective removal of heavy metals from waste effluents thanks to the presence of functional groups which are reactive towards metal ions [36-38].

According to the literature, Chelex 100, Ambelite IRC 748, Purolite S930, Lewatit TP 207, and Diaion CR11 have been frequently applied in removal of $\mathrm{Ni}^{2+}, \mathrm{Cd}^{2+}, \mathrm{Cu}^{2+}$, $\mathrm{Co}^{2+}, \mathrm{Zn}^{2+}, \mathrm{Pb}^{2+}$, and $\mathrm{Cr}^{3+}$ from aqueous solutions [39-40]. Nevertheless, few reports are 
available on removal of heavy metal ions from marine wastes by chelating ion exchanger through sub-critical isothermal treatments. Moreover, distribution of heavy metal ions in distinguished phases resulting from sub-critical treatment has rarely been investigated.

In this work, the effect of temperature on decomposition of squid oil to fatty acids and formation of edible materials has been studied. First, polluted substances were prepared to experience sub-critical water treatment, through which heavy metal ions underwent chelate reaction and entered oil phase and metal-soap phases. Then, removal of heavy metal ions from contaminated phases using CR-11 was carried out. In this regard, a detailed analysis was done to probe the presence of $\mathrm{Cu}^{2+}, \mathrm{Cd}^{2+}, \mathrm{Zn}^{2+}$ and $\mathrm{Pb}^{2+}$ heavy metal ions in three phases formed separately (oil, metal-soap and aqueous) under different sub-critical reaction temperatures. In particular, the effect of temperature on the formation of chelate agents of metal ions in the oil and metal-soap phases was reported. The superiority of removal of heavy metal ions by CR11 exchanger was finally quantified with respect to PEI-chitosan beads and PEI-chitosan fibers experiencing sub-critical treatment under isothermal condition. 


\section{Experimental}

\subsection{Materials}

Crude squid oil was obtained from Riken Vitamin Co. (Tokyo, Japan). Before each treatment, the oil was stored under nitrogen to prevent oxidation in an incubator with temperature fixed at $308 \mathrm{~K}$. The composition of fatty acids contained in the obtained squid oil is given in Table 1. All reagents used in this study were laboratory grade, and the water was milli-Q water (18.2 M-Ohm grade). The salts that contain the metal ions, $\mathrm{Cu}\left(\mathrm{NO}_{3}\right)_{2} \cdot 3 \mathrm{H}_{2} \mathrm{O}, \mathrm{Zn}\left(\mathrm{NO}_{3}\right)_{2} \cdot 6 \mathrm{H}_{2} \mathrm{O}, \mathrm{Cd}\left(\mathrm{NO}_{3}\right)_{2} \cdot 4 \mathrm{H}_{2} \mathrm{O}$, and $\mathrm{Pb}\left(\mathrm{NO}_{3}\right)_{2}$ were provided by WAKO Chemical, Japan. Nitric acid (Wako Pure Chem. Ind.) was used in pretreatment of metal before the analysis. Metal standard solutions for the induced coupled plasma (ICP) analysis were obtained from Kishida Chemicals Co. (Osaka, Japan), and Wako Pure Chemicals Industries Ltd (Osaka, Japan). According to ICP analysis, no heavy metal ion was found in the oil. 
Table 1. Composition of squid oil.

\begin{tabular}{lclc}
\hline \hline Fatty acids & $\begin{array}{c}\text { Percentage } \\
\text { composition }\end{array}$ & $\begin{array}{l}\text { Fatty acids } \\
(\%)\end{array}$ & $\begin{array}{c}\text { Percentage } \\
\text { composition }\end{array}$ \\
\hline \hline Myristic, $\mathrm{C}_{14: 0}$ & 4.3 & Linoleic, $\mathrm{C}_{18: 2}$ & 1.4 \\
Pentadecylic, $\mathrm{C}_{15: 0}$ & 0.3 & Linolenic, $\mathrm{C}_{18: 3}$ & 0.6 \\
Palmitic, $\mathrm{C}_{16: 0}$ & 16.3 & Octadecatetraenoic, $\mathrm{C}_{18: 4}$ & 1.1 \\
Palmitoleic, $\mathrm{C}_{16: 1}$ & 4.4 & Eicosenoic, $\mathrm{C}_{20: 1}$ & 9.9 \\
Hexadecadienoic, $\mathrm{C}_{16: 2}$ & 1.7 & Arachidonic, $\mathrm{C}_{20: 4}$ & 1.2 \\
Margaric, $\mathrm{C}_{17: 0}$ & 0.9 & EPA, $\mathrm{C}_{20: 5}$ & 13.7 \\
Stearic, $\mathrm{C}_{18: 0}$ & 2.4 & Docosenoic, $\mathrm{C}_{22: 1}$ & 6.0 \\
Oleic, $\mathrm{C}_{18: 1}$ & 15.1 & DHA, $\mathrm{C}_{22: 6}$ & 20.7 \\
\hline
\end{tabular}

The ion exchangers used in this work were commercial chelate ion exchanger,

DIAION CR11 (Mitsubishi Chemical Co., Japan), PEI-chitosan beads and PEI-chitosan fiber (Fuji Spining Co., Japan). The DIAION CR11 was made of the styrene-divinylbenzene, and its functional group was iminodiacetic acid $\left(-\mathrm{CH}_{2} \mathrm{~N}\left(\mathrm{CH}_{2} \mathrm{COO}\right)_{22^{-}}\right)$. The physical properties of the CR11 are given in Table 2.

Table 2. Experimental values and conditions.

\begin{tabular}{lcccc}
\hline \hline Resin & $\begin{array}{c}\text { Type of } \\
\text { Resin }\end{array}$ & $\begin{array}{c}\text { Adsorbates } \\
\text { Used }_{(\mathrm{aq})}\end{array}$ & $\begin{array}{c}\text { Initial Concentrations } \\
\left(\mathrm{kmol} / \mathrm{m}^{3}\right)\end{array}$ & $\begin{array}{c}\text { Temperatur } \\
(\mathrm{K})\end{array}$ \\
\hline \hline DIAION & & $\mathrm{Cu}(\mathrm{II})$ & $0.0003 \sim 0.01$ & \\
CR11 & $\mathrm{Na}^{+}$ & $\mathrm{Zn}(\mathrm{II})$ & $0.0003 \sim 0.008$ & 298 \\
(Gel Type) & & $\mathrm{Cd}(\mathrm{II})$ & $0.0002 \sim 0.008$ & \\
& & $\mathrm{~Pb}$ (II) & $0.0002 \sim 0.008$ & \\
\hline
\end{tabular}


PEI-chitosan beads are prepared via magnetic gelatin. The iron ions are distributed in the gelatin period by electrostatic interactions to form iron oxide nanoparticles using a basic solution prepared at high temperatures. The resulting product was further crosslinked for the sake of mechanical stability achievement. PEI-chitosan cationic copolymers were then attached to the surface of magnetic composite. Details on fabrication of PEI-chitosan can be found in the literature [11-13].

The concentration of functional group in PEI-chitosan fiber was determined by the equilibrium isotherm for adsorption of $\mathrm{HCl}$. Titration was performed with methylene blue indicator to determine the concentration of $\mathrm{HCl}$.

The equilibrium isotherm describing the adsorption of HCL on PEI-chitosan can be expressed by the following reaction:

$$
\mathrm{R}-\mathrm{N}+\mathrm{HCl} \stackrel{K_{\mathrm{HCl}}}{\longleftarrow} \mathrm{R}-\mathrm{NH}^{+} \mathrm{Cl}^{-}
$$

where R-N stands for PEI-CH exchanger. Applying mass conservation law to Eq. (1),

Eq. (2) is yielded:

$$
K_{\mathrm{HCl}}=\frac{q_{\mathrm{HCl}}}{[\mathrm{R}-\mathrm{N}] \cdot C_{\mathrm{HCl}}}
$$

The total ion-exchange capacity is given by Eq. (3) as follows:

$$
Q=q_{\mathrm{HCl}}+[\mathrm{R}-\mathrm{N}]
$$

Combining Eq. (2) and Eq. (3), the Langmuir equation, Eq. (4), is derived: 


$$
q_{\mathrm{HCl}}=\frac{K_{\mathrm{HCl}} Q C_{\mathrm{HCl}}}{1+K_{\mathrm{HCl}} C_{\mathrm{HCl}}}
$$

The saturation capacity $Q\left[\mathrm{~mol} \cdot \mathrm{m}^{-3}\right.$ wet resin $]$ and the equilibrium constant $K_{\mathrm{HCl}}$ $\left[\mathrm{m}^{3} \cdot \mathrm{mol}^{-1}\right]$ can be obtained from Eq. (5), the so-called transformed from of Eq. (4):

$$
\frac{C_{\mathrm{HCl}}}{q_{\mathrm{HCl}}}=\frac{1}{K_{\mathrm{HCl}} Q}+\frac{C_{\mathrm{HCl}}}{Q}
$$

The solid line in Fig. 1 obtained using values of $K_{\mathrm{HCl}}$ and $Q$ listed in Table 3 correlates well the Langmuir isotherm corresponding to PEI-chitosan adsorbent.

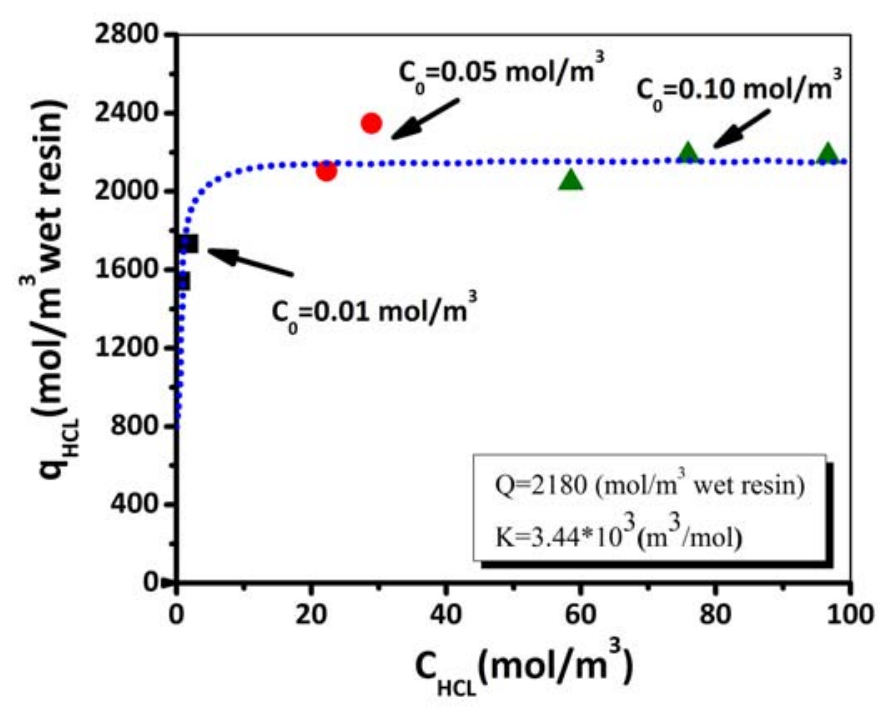

Fig. 1. Experimental equilibrium isotherm for the adsorption of $\mathrm{HCl}$ on $\mathrm{PEI}-\mathrm{chitosan}$ 
Table 3. Physical properties of PEI-chitosan beads and PEI-chitosan fiber.

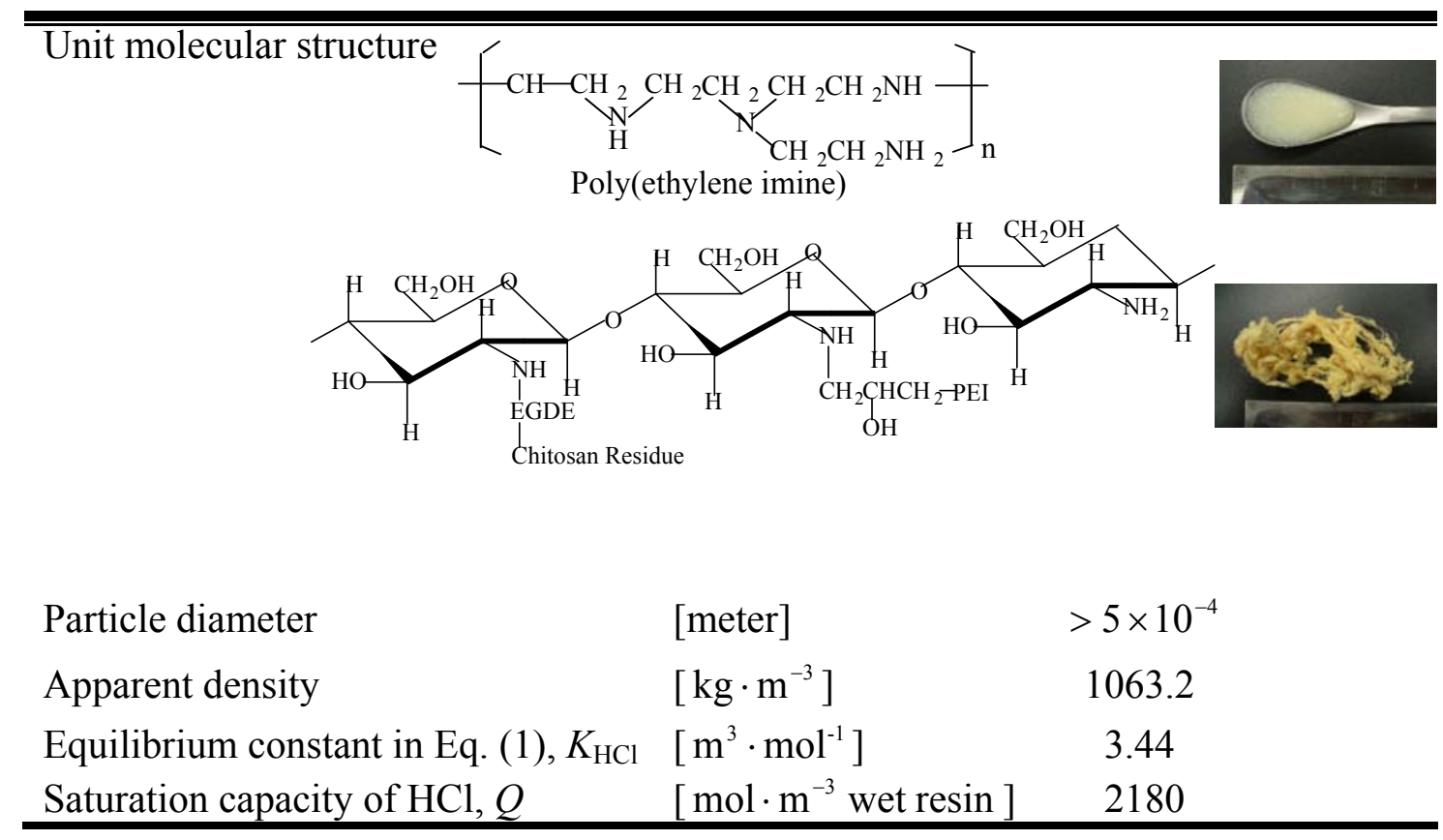

In case of CR11, the main reaction takes place through the following scheme:

$$
\mathrm{R}-\mathrm{NH}_{2}+\mathrm{HCl} \stackrel{K_{H C l}}{\longleftarrow} \mathrm{R}-\mathrm{NH}_{3} \mathrm{Cl}
$$

Eq. (7) gives the following Langmuir equation [41]:

$$
q=\frac{Q K_{\mathrm{HCl}}}{1+K_{H C L}}
$$

where $\mathrm{q}(\mathrm{mg} / \mathrm{g})$ is the equilibrium amount of adsorbate, $\mathrm{Q}$ is the Langmuir constants and $K_{H C L}$ is a constant of chemical reaction. The equilibrium data were corellated well with the Langmuir plot. In $\mathrm{Na}^{+}$-type DIAION CR11, the reaction can be stated by Eq. (8):

$$
\mathrm{R}-\mathrm{Na}^{+}+\mathrm{H}^{+} \underset{\mathrm{Ka}^{+}}{\stackrel{\mathrm{Na}^{+}}{\longleftarrow}} \mathrm{R}-\mathrm{H}^{+}+\mathrm{Na}^{+}
$$


where R-Na ${ }^{+}$denotes the chelate resin. Applying the mass action law to Eq. (8), we can derive Eq. (9):

$$
K_{N a^{+}}^{H^{+}}=\frac{q_{H^{+}} C_{N a^{+}}}{q_{N a^{+}} C_{H^{+}}}
$$

where $K_{\mathrm{Na}^{+}}^{H^{+}}$is a equilibrium constant of chemical reaction, $\mathrm{q}_{\mathrm{H}+}$ and $\mathrm{q}_{\mathrm{Na}}$ are equilibrium amount of $\mathrm{H}+$ and $\mathrm{Na}^{+}$ions and also $\mathrm{C}_{\mathrm{Na}}$ and $\mathrm{C}_{\mathrm{H}+}$ are concentarion of $\mathrm{H}^{+}$ and $\mathrm{Na}^{+}$. The conditions of electro-neutrality are given by:

$$
\begin{aligned}
& \psi=q_{\mathrm{H}^{+}}+q_{\mathrm{Na}^{+}} \\
& C_{0}=C_{\mathrm{H}^{+}}+C_{\mathrm{Na}^{+}}
\end{aligned}
$$

when Eq. (9) to Eq. (11) are combined, we obtain Eq. (12):

$$
q_{H^{+}}=\psi-\frac{1}{K_{N a^{+}}^{H^{+}}}\left(C_{0}-C_{H^{+}}\right) \frac{q_{H^{+}}}{C_{H^{+}}}
$$

The saturation capacity $\psi\left[\right.$ mole/kg dry-resin] and the equilibrium constant $K_{\mathrm{Na}^{+}}^{H^{+}}[\mathrm{kg}$ dry-resin/mole] were determined from Eq. (13), i.e. the transformed from of Eq. (12):

$$
C_{H^{+}}=-\frac{1}{K}\left(C_{0}-C_{H^{+}}\right)+\psi \frac{C_{H^{+}}}{q_{H^{+}}}
$$

The physical properties of DIAION CR11 are given in Table 4. Again, the solid line in Fig. 2 representing the isotherm obtained by the values of $K$ and $Q$ given in Table 4, matches well the experimental data. 
Table 4. Physical properties of DIAION CR11 used in this study.

\begin{tabular}{|c|c|c|}
\hline \multicolumn{3}{|l|}{ Unit molecular structure } \\
\hline Particle size range (dry) & US standard mesh & $24-28$ \\
\hline Particle diameter (dry) & meter & $6.756 \times 10^{-4}$ \\
\hline True density & $\mathrm{kg}$ of dry-resin $/ \mathrm{m}^{3}$ & 1255 \\
\hline Saturation capacity of $\mathrm{HCl}, Q$ & mole/kg dry-resin & 1.395 \\
\hline Equilibrium constant in Eq. (6), $K_{H^{+}}$ & kg dry-resin/mole & $1.723 \times 10^{3}$ \\
\hline
\end{tabular}




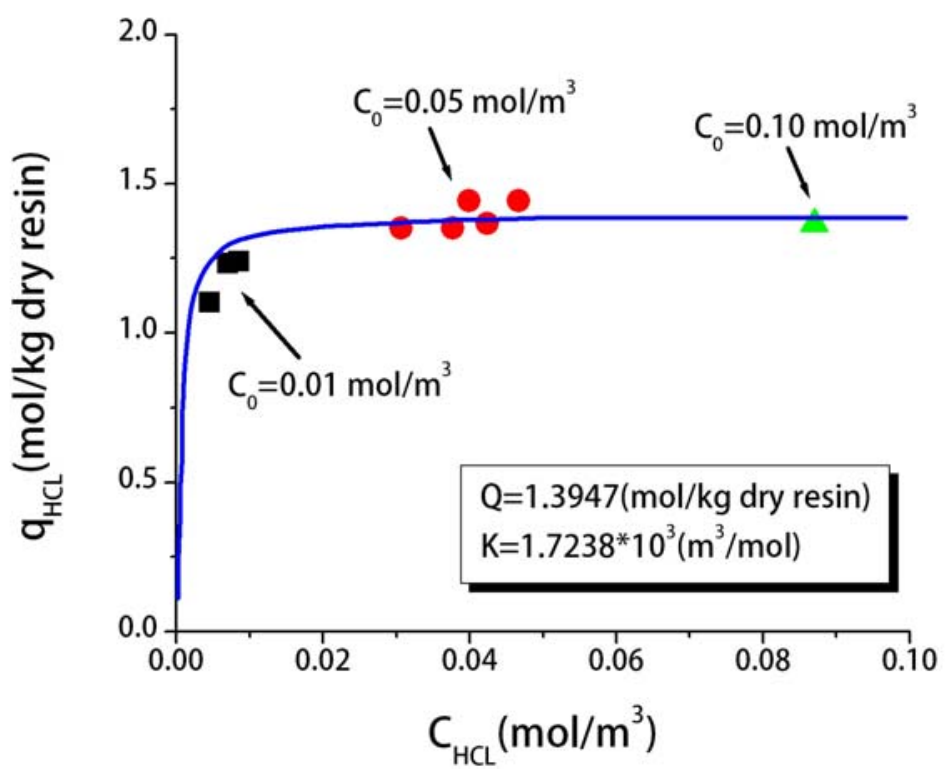

Fig. 2. Experimental equilibrium isotherm for the adsorption of $\mathrm{HCl}$ on DIAION CR11

\subsection{Sub-critical water (Sub-CW) treatment}

The reaction between metal ions (concentration of $0.01 \mathrm{M}$ for each metal aqueous solution) in aqueous solution and the squid oil was carried out using stainless steel pipes (SUS16, i.d. $0.02 \mathrm{~m} \times 0.20 \mathrm{~m}$, reactor volume $70.0 \mathrm{~cm}^{3}$ ) with Swagelok caps. The dissolved oxygen in the sample was degassed by purging argon gas. The reactor was then sealed by Swagelok caps and immersed in a preheated molten salt bath (Thomas Kagaku Co. Ltd., Celsius 600H) as shown in Fig. 3. 


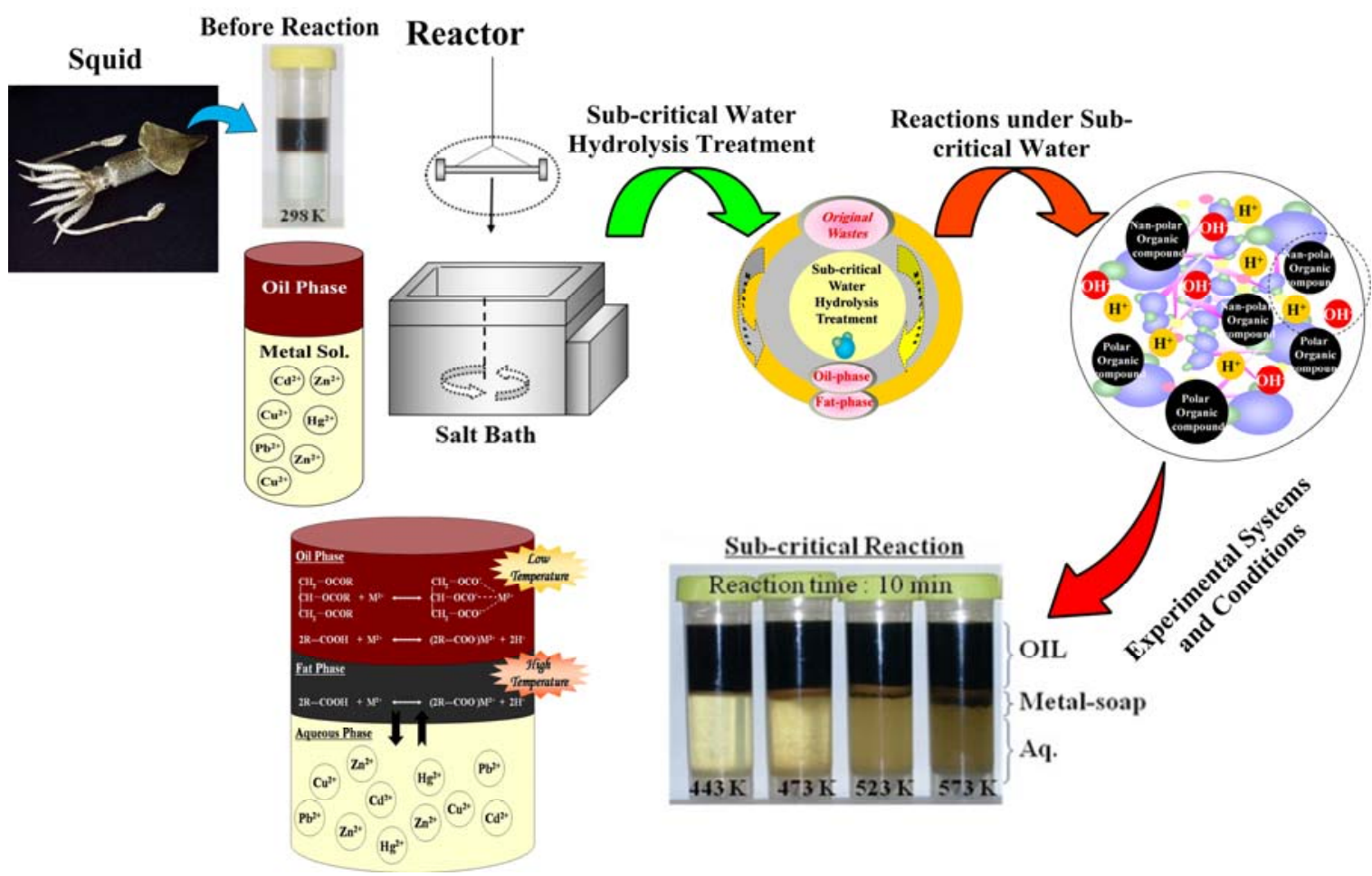

Fig. 3. Schematic of batch experimental set-up and samples' appearance before and after sub-CW reaction

The reactor kept under shaking in the salt bath at the course of reaction. The reactions were carried out at temperature range $473-673 \mathrm{~K}$, and the pressure range was $1.35-8.5$ $\mathrm{MPa}$, as estimated from the available steam tables. The reactor was subsequently removed from the thermal bath and rapidly quenched by wringing out in a cold water bath. During the sub-CW reaction, free fatty acids are to be produced in the oil phase (OIL) according to the hydrolyzed reaction of Eq. (14):

$$
\begin{array}{lll}
\mathrm{CH}_{2}-\mathrm{OCOR}_{1} \\
\mathrm{CH}-\mathrm{OCOR}_{2} \\
\mathrm{CH}_{2}-\mathrm{OCOR}_{3}
\end{array}+3 \mathrm{H}_{2} \mathrm{O} \longleftrightarrow \begin{gathered}
\mathrm{O} \\
\mathrm{CH} \\
\mathrm{CH}-\mathrm{OH} \\
\mathrm{CH}
\end{gathered}+\begin{aligned}
& \mathrm{R}_{1}-\mathrm{C}-\mathrm{OH} \\
& \mathrm{R}_{2}-\mathrm{CO}-\mathrm{OH} \\
& \mathrm{R}_{3}-\mathrm{OH}-\mathrm{OH} \\
& \mathrm{O}
\end{aligned}
$$


Fig. 3 illustrates the formation of OIL and metal-soap phase. After the sub-CW reaction, OIL (upper phase) and aqueous (lower phase) were analyzed. As a consequence of sub-CW and the presence of heavy metal ions, both triglycerides and free fatty acids underwent complex reactions with metal ions. The extraction of metal ions from aqueous solution to the OIL was occurred based on the complex formation reactions of triglyceride molecules with metal ions, taking place according to Eq. (15):



On the other hand, heavy metal ions were extracted by the strong chelate reaction with the free fatty acids produced through reaction scheme shown in Eq. (14) and produced metal-soap phase as shown in Eq. (16). Metal ions could react with glyceride molecules and fatty acids via $\mathrm{O}$ donor atom of carboxylic group of the free fatty acids to form stable complexes. [26, 27]<smiles>[R]C(=O)O[PH2+][C@H](C)C([R])=O</smiles> 


\subsection{Ion exchange process}

The ion exchange particles were properly conditioned to obtain the $\mathrm{R}-\mathrm{Na}$-form. A sufficient amount of resin granules was placed in a glass column with an internal diameter of $3.5 \mathrm{~cm}$ and height of $100 \mathrm{~cm}$, and then sufficient amount of deionized water was added to fill the gap between particles. The conditioning started with an acid washing, where $2000 \mathrm{~cm}^{3}$ of $1.0 \mathrm{kmol} \cdot \mathrm{m}^{-3} \mathrm{HCl}$ aqueous solution was run through the column bed. This process was repeated under the same concentration of $\mathrm{HCl}$ aqueous solution and then terminated when the inlet and the outlet $\mathrm{pH}$ of the column became equal. The resin particles were then thoroughly rinsed with deionized water. Next, a series of $2000 \mathrm{~cm}^{3}$ of $1.0 \mathrm{kmol} \cdot \mathrm{m}^{-3} \mathrm{NaOH}$ aqueous solutions were run through the column bed. Likewise, the $\mathrm{pH}$ at the inlet and the outlet of the column was measured continuously until equality was attained. The resin particles were again thoroughly washed with deionized water. Finally, the resin particles were dried under vacuum.

To elucidate the ability and suitability of chelate ion exchanger (DIAION, CR11), the adsorption results due to this resin were compared with two commonly used ion exchangers; first, a new weakly basic resin, polyaminated highly porous PEI-chitosan bead and second, PEI-chitosan fibers which were used to uptake metal ions from different aqueous solutions [42-43]. 


\subsection{Heavy metal removal measurements}

Decomposition of squid oil under different temperatures of $273,473,573$ and $673 \mathrm{~K}$ was investigated by GC-MS analysis. Samples were characterized at electron impact mode $(70 \mathrm{eV})$ using a Shimadzu GC-17A GCMS-QO5050 gas chromatography mass spectrometer. The GC instrument was equipped with a $0.2 \mu \mathrm{m}$ film thickness of $100 \%$ dimethylpolysiloxane UA-1 ultra-alloy capillary column (Frontier Laboratories Ltd., Fukushima, Japan) of $15 \mathrm{~m} \times 0.25 \mathrm{~mm}$ i.d.

The presence of heavy metal ions in squid oil was analyzed by Seiko atomic absorption spectrophotometer (Model SAS 7500A) with D2 deuterium lamp background correction in air acetylene flame absorption mode. Metal concentrations in aqueous phase were also detected by direct aspiration into the flame atomic absorption. Cadmium, copper and zinc were respectively analyzed at wavelengths of $228.8,324.75$, and $213.86 \mathrm{~nm}$. The ion concentrations were calculated according to calibration standards. The detection limit for analyzing metal ions was measured as follows: $0.05 \mathrm{ppm}$ for $\mathrm{Cd}^{2+}, 0.05 \mathrm{ppm}$ for $\mathrm{Cu}^{2+}$, and $0.02 \mathrm{ppm}$ for $\mathrm{Zn}^{2+}$. In case of $\mathrm{Pb}^{2+}$, atomic absorption spectroscopy was utilized using the flameless cold vapor technique at a wavelength of $253.65 \mathrm{~nm}$.

To efficiently identify the coexisting metal ions, it was known that $\mathrm{Cu}^{2+}, \mathrm{Cd}^{2+}$ and $\mathrm{Zn}^{2+}$ might affect their atomic absorption measurements. From this perspective, specific amounts of $\mathrm{Cu}^{2+}, \mathrm{Cd}^{2+}$ and $\mathrm{Zn}^{2+}$ were added individually to a sample solution and the 
concentrations of the metals were measured assuming a single component system. It was observed that the added ions do not upset the concentrations of $\mathrm{Cd}^{2+}, \mathrm{Cu}^{2+}$ and $\mathrm{Zn}^{2+}$. In turn, multiple experiments were carried out at three temperatures of 473, 513 and $573 \mathrm{~K}$ to obtain reliable values, where a small deviation of ca. $5.0 \%$, at worst, was detected. On account of such an acceptable deviation and minor difference observed in the results, the rest of experiments were performed accordingly.

The equilibrium adsorption isotherms of the metal ions were measured by the batch method. The various measured weights of the resin beads were contacted with the OIL and metal-soap solutions for all concentration ranges and the samples were placed in an incubator under constant stirring at $1200 \mathrm{rpm}$ and an operating temperature of $298 \pm 0.5 \mathrm{~K}$. The ion exchange equilibria were attained in four days, which guaranteed an equilibrium state. Then, metal ion concentration in the equilibrated solutions was determined. Resin-phase concentration of the metal ion $q_{e}[\mathrm{~mole} / \mathrm{kg}$ dry-resin] was calculated using Eq. (17) [44]:

$$
q_{e}=\frac{\left(C_{o}-C_{T}\right) V}{W}
$$

where $C_{o}$ and $C_{T}\left(\mathrm{kmol} . \mathrm{m}^{-3}\right)$ are the initial and the final metal concentrations in the OIL and/or metal-soap, respectively; $V\left(\mathrm{~m}^{3}\right)$ is the volume of the adsorption solution; and 
$W(\mathrm{~kg})$ is the weight of the resin. All experiments were carried out at $298 \mathrm{~K} \pm 0.5 \mathrm{~K}$.

\section{Results and discussion}

\subsection{Detection of heavy metal ions in triple phases}

GC-MS chromatograms of glycerides and fatty acid molecules under different temperatures of squid oil are shown in Fig. 4. According to the figure, the concentrations of glycerides and fatty acids at high temperature are low and high, respectively. This behavior indicates that glyceride bonds are not stable at elevated temperatures to form fatty acids with stable structures. The amount of triglycerides was decreased at $573 \mathrm{~K}$, in turn that of fatty acids was drastically decreased in comparison with squid oil at $473 \mathrm{~K}$. In addition, the amount of glycerides has decreased sharply at 673K. Accordingly, the functional groups in squid oil were changed and squid oil under different temperature had carboxylate ions (-COO-), $\left(-\mathrm{NH}_{2}\right)$ and hydroxyl $(-\mathrm{OH})$ as functional groups (chelating agent) for chelate reaction to metal ions. 


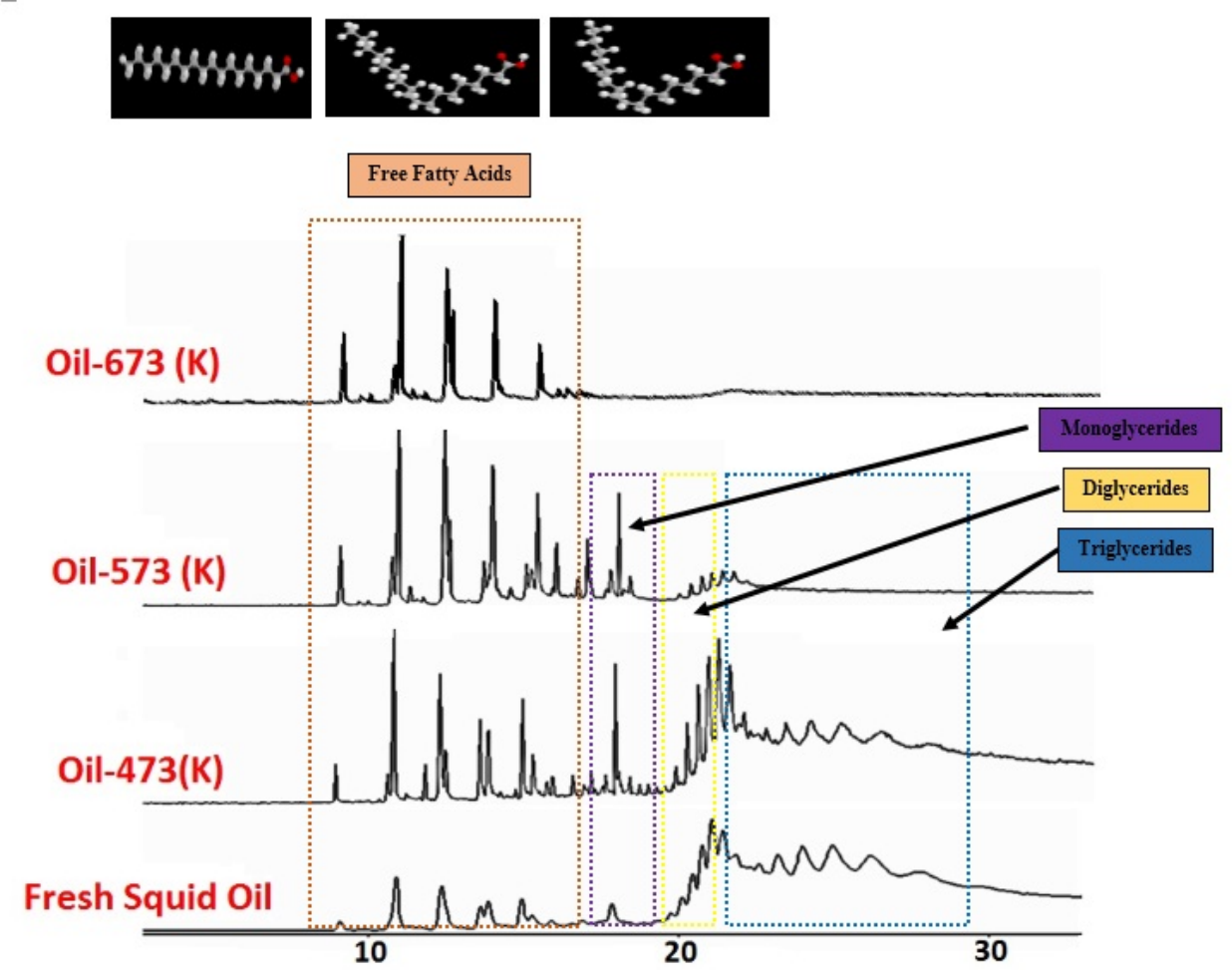

Fig. 4. GC-MS chromatogram of hydrolyzed triglyceride molecules in squid oil at different temperatures

Fig. 5 shows the variation of metal ions concentration in the oil phase as a function of temperature. The initial concentration of heavy metal ions in the aqueous phase was 50 mg. $1^{-1}$. By the time aqueous and oil phases were in contact, heavy metal ions have transferred from aqueous to oil phase. It can be seen that metal ion concentration of $\mathrm{Hg}^{2+}$ was exceptionally very high even at low reaction temperature in comparison with other types of ions, which implies significant affinity of $\mathrm{Hg}^{2+}$ ion towards squid oil. This behavior can be related to the formation of a stable complex between $\mathrm{Hg}^{2+}$ and carbonyl and carboxyl functional groups of the fatty acids and triglycerides in the squid oil [45-46]. It was observed that the concentration of ions followed the order 
$\mathrm{Cu}^{2+}>\mathrm{Pb}^{2+}>\mathrm{Zn}^{2+}>\mathrm{Cd}^{2+}$ with increased temperature.

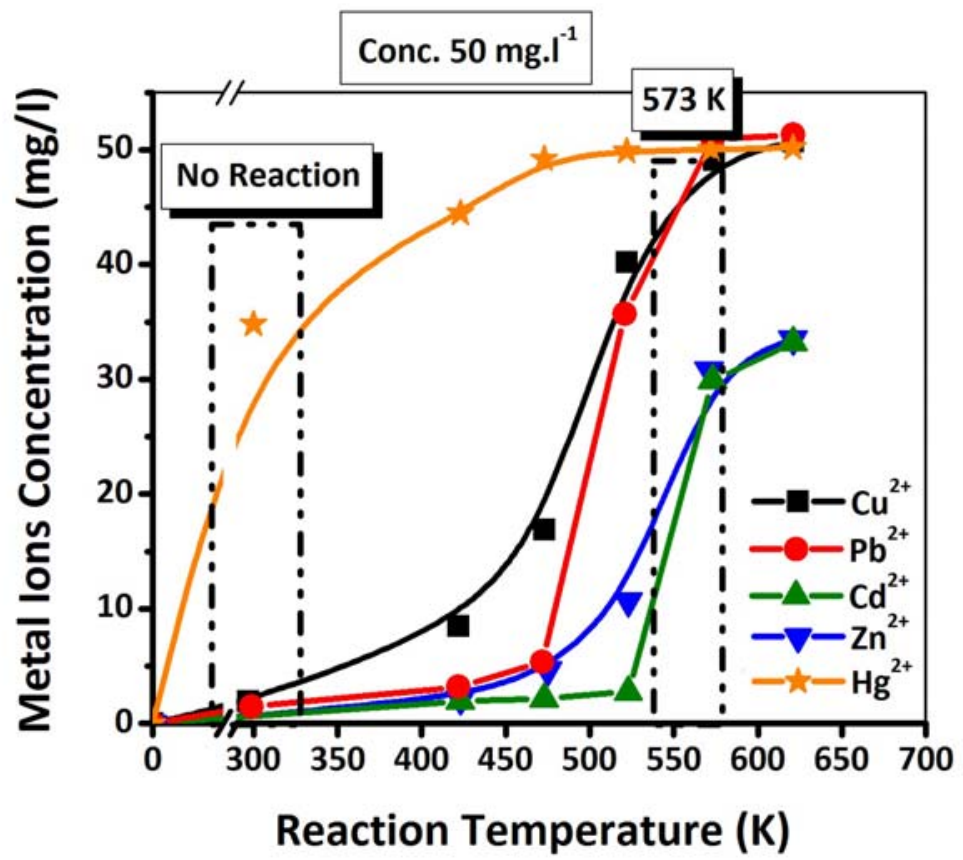

Fig. 5. Alteration of metal concentration in the oil phase as a function of temperature for samples with initial aqueous phase concentration of $50 \mathrm{mg} . \mathrm{l}^{-1}$.

Moreover, the rate of chelate reaction of $\mathrm{Cu}^{2+}$ and $\mathrm{Pb}^{2+}$ ions has increased at high temperatures. This behavior can be explained on account of formation of stable complex ions with strong functional groups. Moreover, chelate of ions at reaction temperature of $473 \mathrm{~K}$ was facilitated. In view of previous section on the level of glycerides and fatty acids existed in squid oil at $473 \mathrm{~K}$, the chelate reaction rates of ions are significant. At elevated reaction temperatures, fatty acids play the major role in chelate formation process and carboxyl functional groups from these fatty acids are apt to chelate of ions in comparison to carbonyl groups in all glycerides [45]. At temperatures above 550K, 
chelate formation of ions reached the highest possible level experiencing a plateau. It is believed that such metal ions might be absorbed on the $-\mathrm{NH}_{2}$ and $-\mathrm{COOH}$ groups of proteins due to the squid entrails [27]. Fig. 6 shows the effect of reaction temperature on the yield of OIL and metal-soap phases produced during sub-CW reactions. It is observed that an increase of temperature leads to formation of more triglycerides in the OIL, which are hydrolyzed to free fatty acids (Eq. (14)). As a result, a decrease in the OIL yield is observed. Unlike this, the completion of produced free fatty acids and metal ions (Eq. (16)) increases the metal-soap yield.

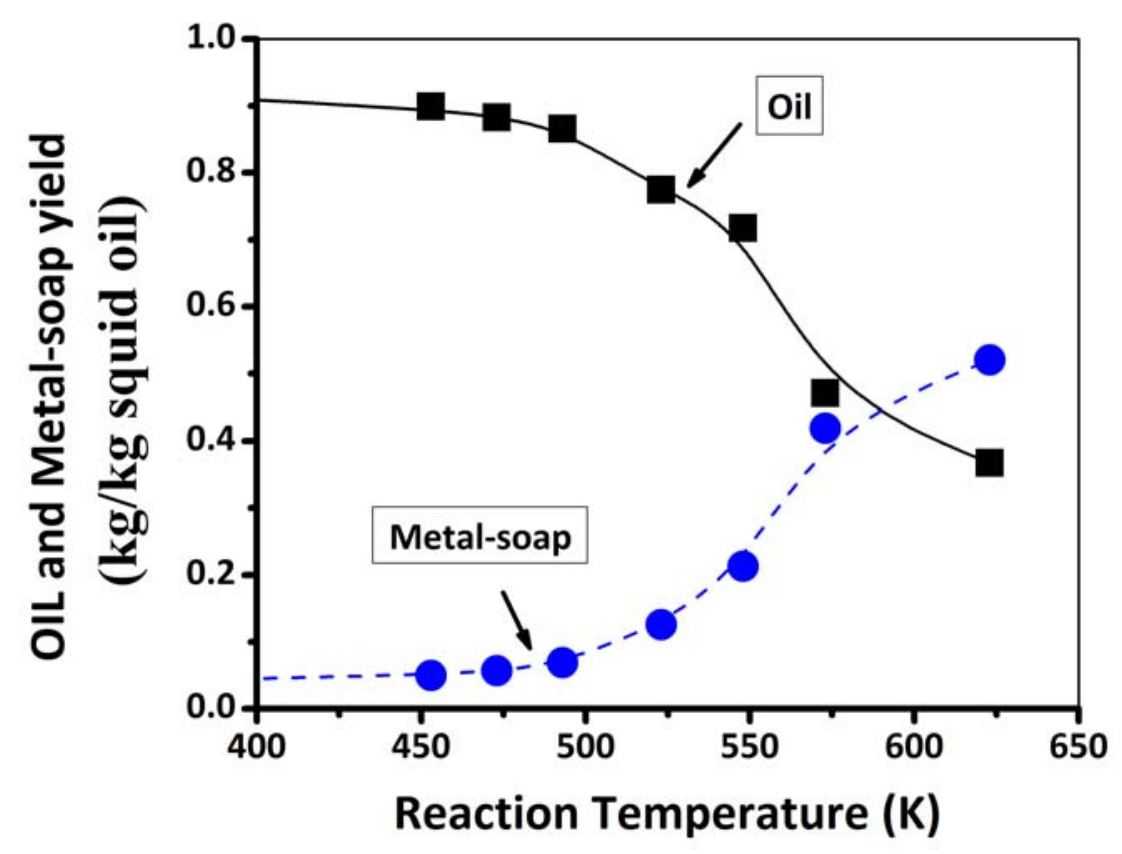

Fig. 6. Effect of reaction temperature on the yield of OIL and metal-soap phases

Fig. 7 depicts the effect of temperature on the concentrations of $\mathrm{Cu}^{2+}, \mathrm{Pb}^{2+}, \mathrm{Cd}^{2+}$ and 
$\mathrm{Zn}^{2+}$ ions in the aqueous, OIL and metal-soap phases at reaction time of $10 \mathrm{~min}$. The concentration of metal ions in the aqueous solution is shown in Fig. 7A. Generally, it can be seen that ion concentration decreases upon increase of reaction temperature. This behavior indicates that the heavy metal ions are absorbed by functional groups such as $\left(-\mathrm{NH}_{2}\right),(-\mathrm{COOH})$ and $(-\mathrm{OH})$ and, therefore, ion concentrations decreased in aqueous phase.

In case of $\mathrm{Cu}^{2+}$, however, ion concentration was constantly decreased with increasing temperature, but different behaviors were observed regarding of other ions chelation. The ion concentrations of $\mathrm{Pb}^{2+}, \mathrm{Cd}^{2+}$ and $\mathrm{Zn}^{2+}$ were virtually constant, decreasing slightly with temperature, at temperatures in the range of 400-500 K. However, a sharp decrease was observed at temperature range of 500-550K, which can be attributed further to the formation of active sites and replacement of high to low molecular weight fatty acids with are scavenged by the functional groups [26, 47]. Fig. 7B shows the effect of reaction temperature on the ions' concentration in OIL phase. Overall, expect for $\mathrm{Cu}^{2+}$, affinity to OIL phase does not resemble to the aqueous phase. The chelation of $\mathrm{Cu}^{2+}$ vs. temperature followed a parabolic curve with a maximum concentration of $5.5 \times 10^{-3}(\mathrm{~mol} / \mathrm{l})$ at $493 \mathrm{~K}$, then, temperature rise caused a negative effect on this mechanism for $\mathrm{Cu}^{2+}$. These results suggest that by increasing the temperature the amount of oil phase decreased due to saturation of functional groups by the metal ions. 
Moreover, the binding of $\mathrm{Cu}^{2+}$ to fatty acids in OIL phase should be different with aqueous phase. The chelation behavior of $\mathrm{Pb}^{2+}$ and $\mathrm{Cd}^{2+}$ was the same in the OIL phase and showed an ascending trend, achieving maximum values of $5.7 \times 10^{-3}(\mathrm{~mol} / \mathrm{l})$ and $5.0 \times 10^{-3}(\mathrm{~mol} / \mathrm{l})$ at $573 \mathrm{~K}$, respectively. This emphasizes the formation of electrostatic forces between $\mathrm{Pb}^{2+}$ and $\mathrm{Cd}^{2+}$ ions and active site, which stabilizes then at higher temperatures. By contrast, concentration of $\mathrm{Zn}^{2+}$ ion shows a slight increase with increasing temperature. The electrostatic forces between $\mathrm{Zn}^{2+}$ and active sites of glycerides in oil phase have shown a moderate variation at high temperatures. The effect of temperature on variation of ions concentrations in metal soap phase is shown in Fig. 7C. As a whole, the ion concentration increased with increasing temperature. This behavior indicated that chelate reaction of metal ions in chelate sites of fatty acids and triglycerides had direct relation with the temperature. The difference between ion concentrations observed for $\mathrm{Cu}^{2+}$ is greater compared to the other ions. The same story accounted for OIL phase seems to be true for $\mathrm{Pb}^{2+}$ and $\mathrm{Cd}^{2+}$. On the other hand, chelation behavior of $\mathrm{Cu}^{2+}$ and $\mathrm{Zn}^{2+}$ were completely different in oil and metal soap phases. These ion concentrations trends were ascending until $520 \mathrm{~K}$, reaching a plateau at higher temperatures. These trends were attributed to the decomposition of glycerides and production of fatty acids, as well as formation of effective electrostatic bonds between the ions and active sites. In this sense, the developed electrostatic bonds in the 
case of $\mathrm{Cu}^{2+}$ were appropriate and possibly were increased by temperature. Besides, formation of chelate is not so imaginable compared to decomposition of this reaction with increasing temperature such as:

$$
2 \mathrm{R}-\mathrm{COOH}+\mathrm{M}^{2+} \rightleftarrows\left(\mathrm{R}-\mathrm{COO}^{-}\right)_{2} \mathrm{M}^{2+}+2 \mathrm{H}^{+}
$$


Fig. 7. Metal ion distribution in aqueous, metal-soap and OIL phases after sub-CW reactions 


\subsection{Adsorption of heavy metal ions from squid oil to ion exchanger}

Fig. 8 shows the equilibrium adsorption of $\mathrm{Cu}^{2+}, \mathrm{Zn}^{2+}$ and $\mathrm{Pb}^{2+}$ by DIAION CR11, PEI-chitosan beads and PEI-chitosan fiber from the OIL phase (obtained at sub-CW under $523 \mathrm{~K}$ and a reaction time of $10 \mathrm{~min}$ ). Although PEI-chitosan resins have strong affinity to uptake metal ions from the aqueous solution due to their amino functional group [48-49], for oil solution the selectivity of adsorption for CR11 has significantly increased compared to the other two PEI-chitosan resins, especially for $\mathrm{Zn}^{2+}$. This specific behavior of CR11, which leads to at least a five-fold larger exchange capacity compared to PEI-chitosan bead and PEI-chitosan fiber, has been exceedingly influenced by the iminodiacetic functional group and the ability to produce strong chelate complex with metal ions in stable coordinate covalent bonds formation. In the light of the above observation, a schematic model is proposed for the ion adsorption of CR11 and PEI-chitosan resins (Fig. 8C), implying that formation of trap heavy metal ions in CR11 was more effective with respect to PEI-chitosan resin. 

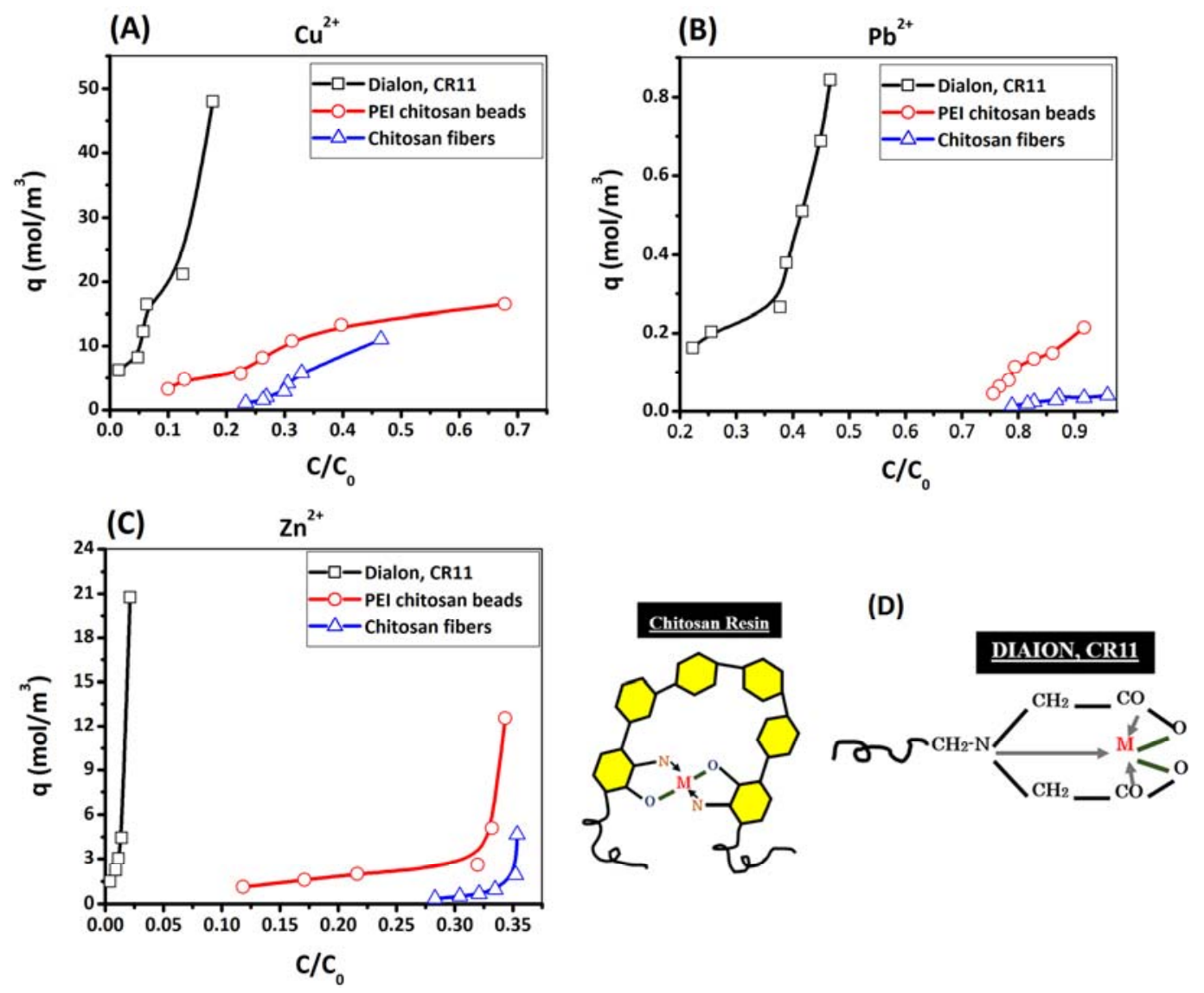

Fig. 8. Equilibrium isotherms for adsorption of heavy metal ions from the oil phase (OIL obtained at $573 \mathrm{~K}$ and $10 \mathrm{~min}$ ) on CR11, PEI-chitosan beads, and PEI-chitosan fiber of (A) $\mathrm{Cu}^{2+}$, (B) $\mathrm{Pb}^{2+},(\mathrm{C}) \mathrm{Zn}^{2+}$ and (D) adsorption mechanism proposed for ion exchangers on CR11 and chitosan.

Experimental equilibrium isotherms for the adsorption of $\mathrm{Cu}^{2+}, \mathrm{Pb}^{2+}, \mathrm{Cd}^{2+}$ and $\mathrm{Zn}^{2+}$ from the OIL phase in single component system are shown in Fig. 9. For each metal ion, the OIL phase containing the high initial concentration of metal was used $\left(0.01 \mathrm{~mol} . \mathrm{m}^{-3}\right.$ of $\mathrm{Cu}^{2+}$ at $498 \mathrm{~K}, 0.008 \mathrm{~mol} . \mathrm{m}^{-3}$ of $\mathrm{Zn}^{2+}$ at $548 \mathrm{~K}, 0.008 \mathrm{~mol} . \mathrm{m}^{-3}$ of $\mathrm{Cd}^{2+}$ at $548 \mathrm{~K}$, and 0.008 mol. $\mathrm{m}^{-3}$ of $\mathrm{Pb}^{2+}$ at $548 \mathrm{~K}$ ). The results suggest that the adsorption selectivity has been favored by $\mathrm{Zn}^{2+}$ and $\mathrm{Cd}^{2+}$ with $100 \%$ uptake of these metal ions from the OIL 
phase followed by $\mathrm{Cu}^{2+}$ and $\mathrm{Pb}^{2+}$.

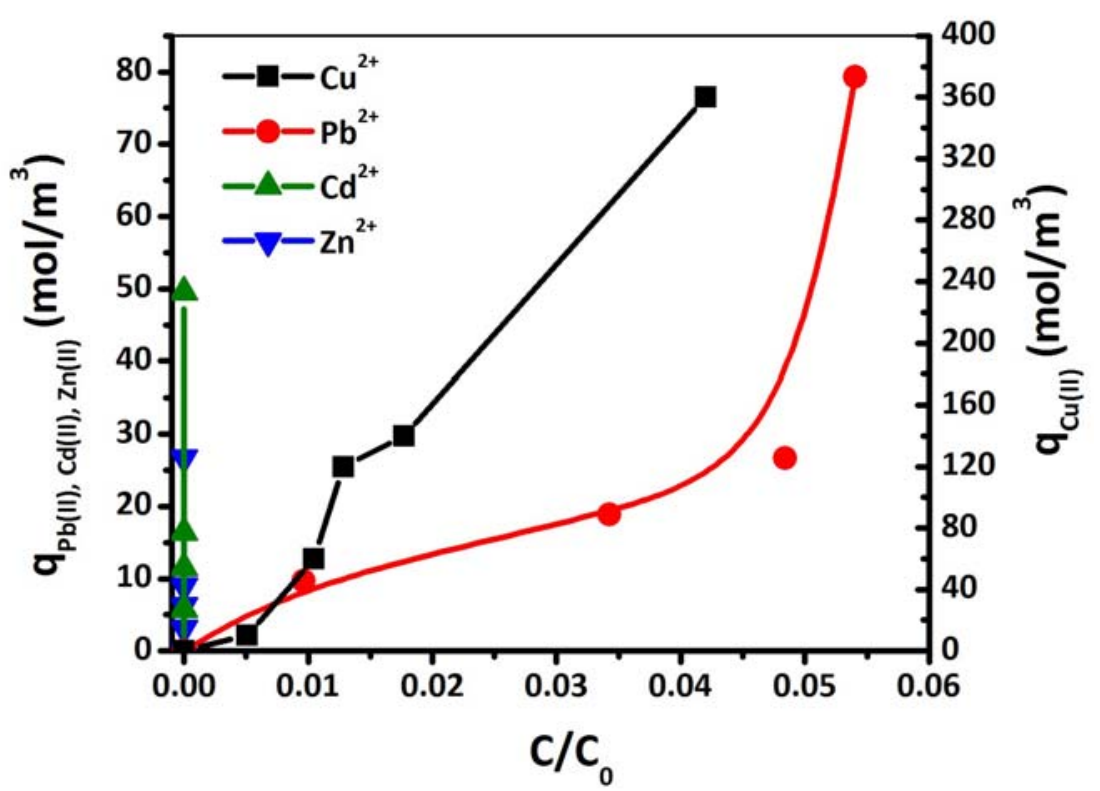

Fig. 9. Equilibrium isotherms for the individual adsorption of $\mathrm{Cu}^{2+}, \mathrm{Pb}^{2+}, \mathrm{Cd}^{2+}$ and $\mathrm{Zn}^{2+}$ from the OIL to DIAION CR11

The adsorption profiles for $\mathrm{Zn}^{2+}$ and $\mathrm{Cd}^{2+}$ are favored through coordination with the nitrogen atom of the iminodiacetic group, while for copper and lead, the adsorption bonds are attributed to the presence of protonated carboxylate anions [50-51]. The relatively high capacity of $\mathrm{Zn}^{2+}$ and $\mathrm{Cd}^{2+}$ to be removed from the OIL phase stems from the selectivity of DIAION, while its adsorption by the CR11 from the aqueous phase is favored for $\mathrm{Cu}^{2+}$ proposing that the selectivity towards OIL phase depends on the ionic strength, ionic radius, the presence of other complex-forming agents and, more importantly, the stability of complex formed between metal ions and OIL phase at different conditions. Moreover, the degree of protonation of the carboxylates and the 
donor $\mathrm{N}$ atom in iminodiacetate group critically affects the ability of the resin to uptake and retain the metal ions.

Fig. 10 depicts the variation of metal ion extraction by the CR11 from the OIL at different sub-CW temperature conditions. Fig. 10A reveals that for the OIL extracted at low temperature $(498 \mathrm{~K})$, the selectivity toward adsorption of $\mathrm{Cu}^{2+}$ is much higher than the others ions and the adsorption of ions follows the order $\mathrm{Cu}^{2+}>>\mathrm{Pb}^{2+}>\mathrm{Zn}^{2+}>\mathrm{Cd}^{2+}$. According to what previously explained in case of Fig. 7 about considerable affinity of $\mathrm{Cu}^{2+}$ to active sites of oil phase, the creation of strong physical bonds between ions and CR11 would be highly probable. The main reason behind this work was to design and examination a suitable resin capable of reacting with heavy metal ions through formation of a more stable complex chelation compared to common adsorbents such as PEI-chitosan beads and fibers, which has been realized using CR11.

The ions $\mathrm{Cd}^{2+}, \mathrm{Zn}^{2+}$ and $\mathrm{Pb}^{2+}$ facilitate the formation of adequate electrostatic bonds between them and active sites in glycerides and fatty acids in the oil phase, which prevents migration of such ions to CR11. Fig. 10B shows ion sorption from ion phase to CR11 at a temperature of $523 \mathrm{~K}$. It can be seen that $\mathrm{Zn}^{2+}$ and $\mathrm{Cd}^{2+}$ are intensely absorbed, where affinity of these ions to active site of CR11 increased by temperature rise and chelates reaction showed sufficient strength (Figures 9C and 9D). This behavior may be due to the decomposition of glyceride and fatty acids molecules in the oil phase 
at high temperatures and then the chelation of $\mathrm{Cu}^{2+}$ decreased surprisingly at high temperatures $(548 \mathrm{~K}$ and $573 \mathrm{~K})$. The difference between chelation behaviors of the $\mathrm{Cu}^{2+}$ can be attributed to the change in electrostatic bonds at high temperatures. The profile of adsorption to CR11 at temperature of $548 \mathrm{~K}$ is shown in Fig. 10C. In such a situation, the rate of ion adsorption followed the order of $\mathrm{Zn}^{2+}>>\mathrm{Cd}^{2+}>>\mathrm{Pb}^{2+}>\mathrm{Cu}^{2+}$. Overall, the extent of the adsorption by CR11 was reduced due to the alteration of adhesion energy between ions and activation sites in the oil phase and CR11.
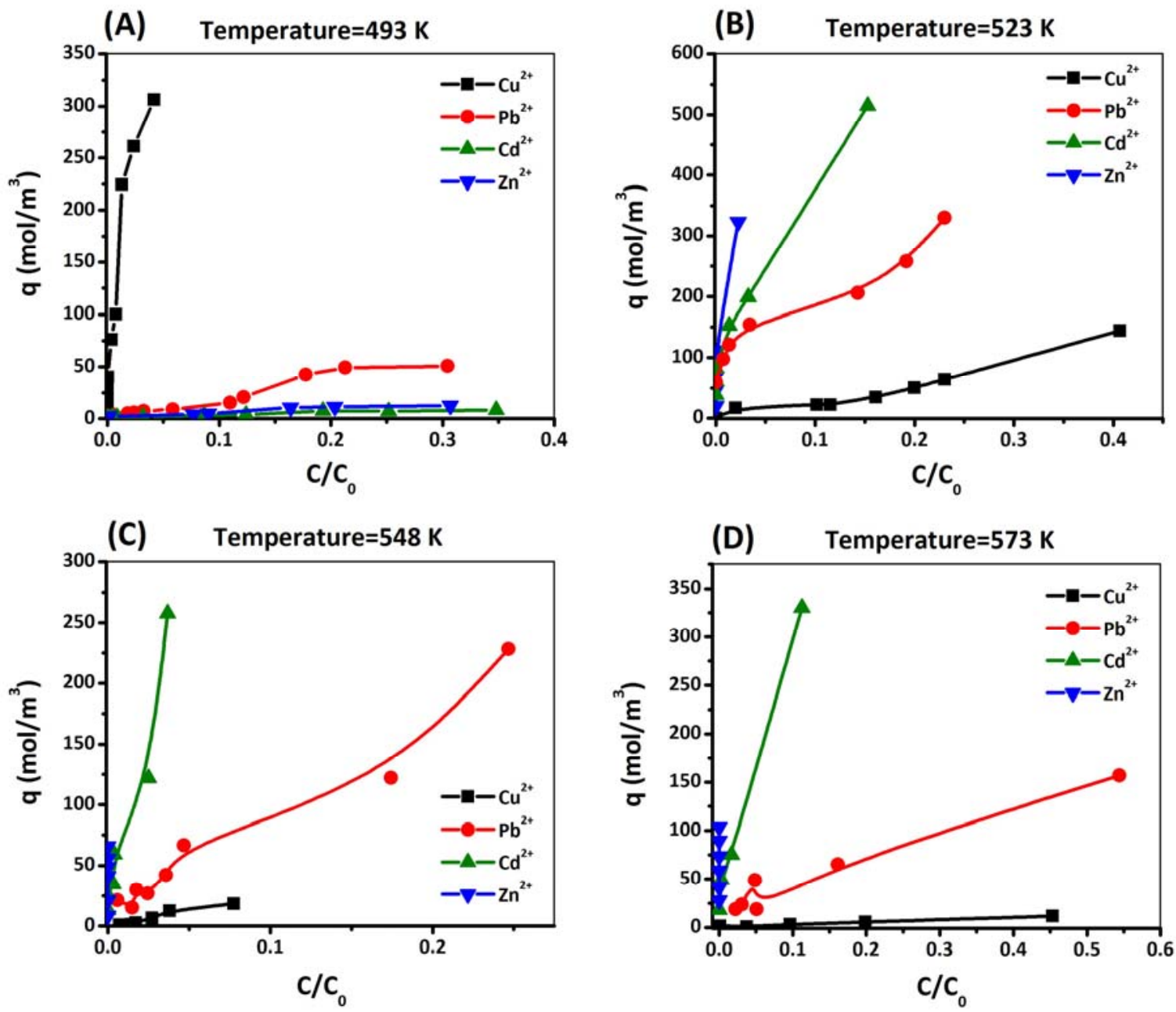

Fig. 10. Equilibrium isotherms for multiple adsorption of $\mathrm{Cu}^{2+}, \mathrm{Pb}^{2+}, \mathrm{Cd}^{2+}$ and $\mathrm{Zn}^{2+}$ from the OIL on DIAION CR11 (A) OIL at $493 \mathrm{~K}$, (B) OIL at $523 \mathrm{~K}$, (C) OIL at $548 \mathrm{~K}$ 
and (D) OIL at $573 \mathrm{~K}$ (all temperature at $10 \mathrm{~min}$ ).

Further increase of temperature to $573 \mathrm{~K}$ still affects adsorption to CR11 (Fig. 10D). As a whole, the observed trends for ion adsorption are similar to the previous figures for OIL obtained at lower temperatures. The rates of ion adsorption for $\mathrm{Zn}^{2+}$ and $\mathrm{Cd}^{2+}$ are significant, whereas for $\mathrm{Cu}^{2+}$ and $\mathrm{Pb}^{2+}$ are limited. It can be concluded that the concentration of $\mathrm{Cu}^{2+}$ in the oil phase is constant, and electrostatic forces between $\mathrm{Cu}^{2+}$ and active sites in oil phase are stronger than in CR11.

The results of adsorption from metal soap phase (at temperature of 573K) to CR11 are shown in Fig. 11 following the order of $\mathrm{Zn}^{2+}>>\mathrm{Cd}^{2+}>>\mathrm{Pb}^{2+}>\mathrm{Cu}^{2+}$.

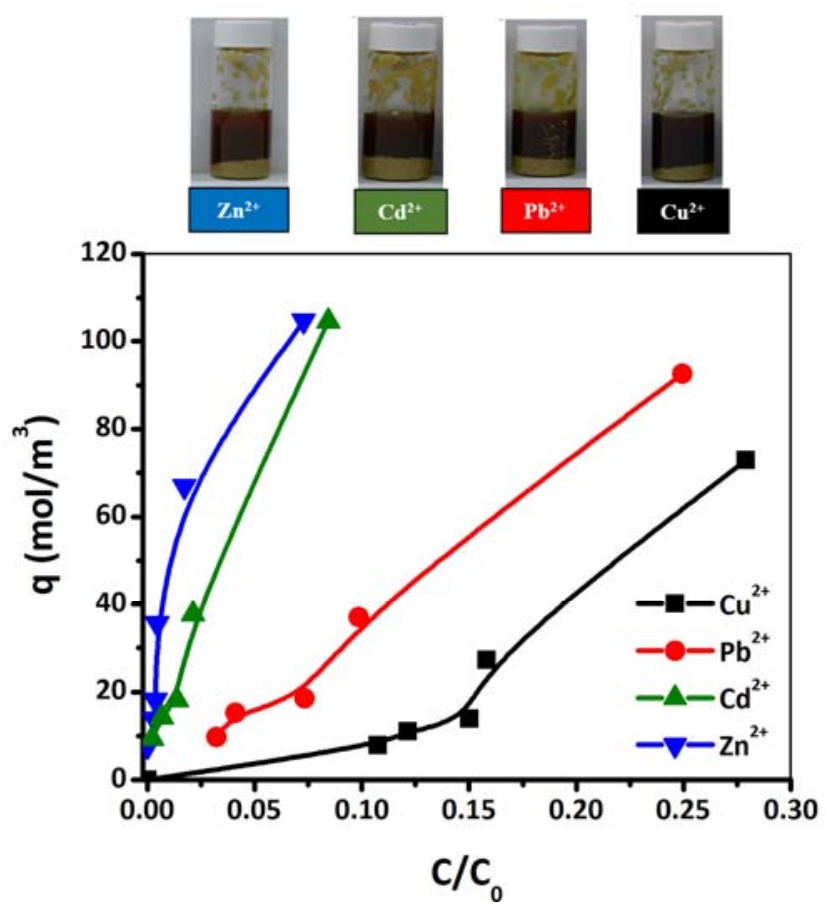

Fig. 11. Equilibrium isotherms for multiple adsorption of $\mathrm{Cu}^{2+}, \mathrm{Pb}^{2+}, \mathrm{Cd}^{2+}$ and $\mathrm{Zn}^{2+}$ from the metal-soap on DIAION CR11 (metal-soap at $573 \mathrm{~K}$ ). 
As previously seen in Fig. 7C, concentration of $\mathrm{Cu}^{2+}$ was high at the assigned temperature implying strong bonds between $\mathrm{Cu}^{2+}$ and functional groups in fatty acids. This can be considered as the main reason to prevent diffusion of $\mathrm{Cu}^{2+}$ to $\mathrm{CR} 11$. On the other hand, strong bonds have not been established between $\mathrm{Cd}^{2+}$ and fatty acids in the metal-soap phase, hence, this ion is apt to be absorbed by the CR11. In this situation, adsorption of $\mathrm{Zn}^{2+}$ by the CR11in metal-soap phase and is noticeable.

\section{Conclusion}

In this work, squid oil was cleaned up through sub-critical water reaction from heavy metal ions followed by desorption of metal ions trapped in squid oil by DIAION and CR11. First, the effect of elevated temperatures on sub-critical treatment was studied by GC analysis, showing that the major part of squid oil was triglycerides. Increase of temperature led to decomposition of triglycerides to fatty acids. At higher temperatures, metal-soap phase was formed containing numerous fatty acids. The presence of heavy metals was investigated in three phases: aqueous, oil and metal-soap. The outcomes confirmed that metal-soap phase provides an ideal condition for chelate reaction of ions because of formation of fatty acids and strong electrostatic bonds between ions and active sites of the fatty acids. Exceptionally, $\mathrm{Cu}^{2+}$ revealed good chelation in metal-soap phase. Next, three kinds of ion exchanger, i.e., CR11, PEI-chitosan beads and 
PEI-chitosan fiber, were applied in adsorption of metal ions from oil phase, where CR11 posed a significant role in trapping ions through formation of strong electrostatic bonds between ions and functional groups in CR11. It was shown that at for OIL obtained at temperature of $493 \mathrm{~K}$ adsorption of $\mathrm{Cu}^{2+}$ was facilitated and underwent promotion upon a temperature rise. The degree of adsorption of $\mathrm{Cu}^{2+}$ decreased in the same direction, while the rate of adsorption of $\mathrm{Zn}^{2+}$ and $\mathrm{Cd}^{2+}$ increased. Moreover, the effect of CR11 on adsorption of ions in metal-soap phase under isothermal condition confirmed that $\mathrm{Zn}^{2+}$ and $\mathrm{Cd}^{2+}$ are responsible for stronger electrostatic bonds in CR11, whereas $\mathrm{Cu}^{2+}$ makes possible electrostatic bonding between ions and functional groups in fatty acids, which itself justifies the low adsorption by CR11.

\section{References}

[1] D. Sud, G. Mahajan, M.P. Kaur, Agricultural waste material as potential adsorbent for sequestering heavy metal ions from aqueous solutions-A review. Bioresour. Technol. 99 (2008) 6017-6027.

[2] N. Wu, H. Wei, L. Zhang, Efficient removal of Heavy metal Ions with biopolymer template synthesized mesoporous titania beads of hundreds of micrometers size. Environ. Sci. Technol. 46 (2012) 419-425. 
[3] P. Rudnicki, Z. Hubicki, D. Kołodynska, Evaluation of heavy metal ions removal from acidic waste water streams. Chem. Eng. J. 252 (2014) 362-373.

[4] T. M. Mututuvari, C. D. Tran, Synergistic absorption of heavy metal ions and organic pollutants by supramolecular polysaccharide composite materials from cellulose, chitosan and crown ether. J. Hazar. Mater. 264 (2014) 449-459.

[5] A. Dabrowski, Z. Hubicki, P. Podkoscielny, E. Robens, Selective removal of the heavy metal ions from waters and industrial wastewaters by ion-exchange method. Chemosphere 56 (2004) 91-106.

[6] M.A.P. Cechinel, D. A. Mayer, T. A. Pozdniakova, L. P. Mazur, R. Boaventura, A. R. De Souza, A. A. U. V.J.P. Vilar, Removal of metal ions from a petrochemical wastewater using brown macro-algae as natural cation-exchangers. Chem. Eng. J. 286 (2016) 1-15.

[7] Y.-W. Qiu, Bioaccumulation of heavy metals both in wild and mariculture food chains in Daya Bay, South China. Estuarine. Coas. Shel. Sci. 163 (2015) 7-14.

[8] A. Vega-López, G. Ayala-López, B. P. Posadas-Espadas, H. F. Olivares-Rubio, R. Dzul-Caamal, Relations of oxidative stress in freshwater phytoplankton with heavy metals and polycyclic aromatic hydrocarbons. Comp. Biochem. Physiol. A. 165 (2013) $498-507$. 
[9] J. D. Hamblin, Gods and Devils in the Details: Marine Pollution, Radioactive Waste, and an Environmental Regime circa 1972. Diplomatic History Volume 32, Issue 4, pages 539-560, September 2008.

[10] N. M. Mahmoodi. Surface modification of magnetic nanoparticle and dye removal from ternary systems. J. Ind. Eng. Chem. 27 (2015) 251-259.

[11] N. M. Mahmoodi. Synthesis of magnetic carbon nanotube and photocatalytic dye degradation ability. Environ. Monit. Assess. 186 (2014) 5595-5604.

[12] N. Wanga, X. Wanga, Y. Jiab, X. Lic, J. Yud, B. Dinga. Electrospun nanofibrous chitosan membranes modified with polyethyleneimine for formaldehyde detection. Carbohydra. Polymers 108 (2014) 192-199.

[13] B. Li, F. Zhou, K. Huang, Y. Wang, S. Mei, Y. Zhou,T. Jing. Environmentally friendly chitosan/PEI-grafted magnetic gelatin for the highly effective removal of heavy metals from drinking water. Scientific. Reports. DOI: 10.1038/srep43082

[14] N. M. Mahmoodi. Photocatalytic ozonation of dyes using multiwalled carbon nanotube. J. Mol. Catal. A: Chem. 366 (2013) 254-260.

[15] C. Lampris, J. A. Stegemann, M. Pellizon-Birelli, G.D. Fowler, C.R. Cheeseman, Metal leaching from monolithic stabilised/solidified air pollution control residues. J. Hazard. Mater. 185 (2011) 1115-1123. 
[16] T. E. McKone, S. K. Hammond, Peer Reviewed: Managing the Health Impacts of Waste Incineration. Environ. Sci. Technol. 34 (2000) 380A-387A.

[17] H. Yoshida, M. Terashima, Y. Takahashi, Production of organic acids and amino acids from fish meat by sub-critical water hydrolysis. Production of organic acids and amino Acids from Fish Meat by Sub-Critical Water Hydrolysis. 15 (1999) 1090-1094.

[18] O. Pourali, F. S. Asghari, H. Yoshida, Simultaneous rice bran oil stabilization and extraction using sub-critical water medium. J. Food. Eng. 95 (2009) 510-516.

[19] H. Yoshida, O. Tavakoli, Sub-critical water hydrolysis treatment for waste squid entrails and production of amino acids, organic acids, and fatty acids. J. Chem. Eng. Japan 37 (2004) 253-260.

[20] O. Tavakoli, H. Yoshida, Conversion of scallop viscera wastes to valuable compounds using sub-critical water. Green Chem. 8 (2006) 100-106.

[21] O. Tavakoli, H. Yoshida, Squid oil and fat production from squid wastes using subcritical water hydrolysis: free fatty acids and transesterification. Ind. Eng. Chem. Res. 45 (2006) 5675-5680.

[22] M. M. Azam, A. Waris, N. M. Nahar, Prospects and potential of fatty acid methyl esters of some non-traditional seed oils for use as biodiesel in India. Biomass. Bioenergy. 29 (2005) 293-302. 
[23] D. P. Geller, J. W. Goodrum, Effects of specific fatty acid methyl esters on diesel fuel lubricity. Fuel 83 (2004) 2351-2356.

[24] S. K. Bhatia, D.-H. Yia, Y.-H. Kim, H.-J. Kim, H.-M. Seo, J.-H. Lee, J.-H. Kim, J,-M. Jeon, K.-S. Jang, Y.-G. Kim, Y.-H. Yang, Development of semi-synthetic microbial consortia of Streptomyces coelicolor for increased production of biodiesel (fatty acid methyl esters). Fuel 159 (2015) 189-196.

[25] A. C. Bosch, B. O’Neill, G. O. Sigge, S. E. Kerwath, L. C. Hoffman, Heavy metals in marine fish meat and consumer health: a review. J. Sci. Food. Agric. 96 (2016) 32-48.

[26] O. Tavakoli, H. Yoshida, Effective recovery of harmful metal ions from squid wastes using subcritical and supercritical water treatments. Environ. Sci. Technol. 39 (2005) 2357-2363.

[27] O. Tavakoli, H. Yoshida, Application of sub-critical water technology for recovery of heavy metal ions from the wastes of Japanese scallop Patinopecten yessoensis. Sci. Total. Environ. 398 (2008) 175-184.

[28] T. Rogalinski, S. Herrmann, G. Brunner, Production of amino acids from bovine serum albumin by continuous sub-critical water hydrolysis. J. Supercr. Fluids 39 (2005) 49-58. 
[29] A. K. M. Asaduzzaman, B.-S. Chun, Recovery of functional materials with thermally stable antioxidative properties in squid muscle hydrolyzates by subcritical water. J. Food. Sci. Tech. 52 (2015) 793-802.

[30] J. Viganó, A. P. F. Machado, J. Martínez, Sub- and supercritical fluid technology applied to food waste processing. J. Supercr. Fluids 96 (2015) 272-286.

[31] B. Shah, U. Chudasama, Synthesis and characterization of a novel hybrid material as Amphoteric ion exchanger for simultaneous removal of cations and anions. J. Hazard. Mater. 276 (2015) 138-148.

[32] B. Shah, U. Chudasama, Synthesis and characterization of a novel hybrid chelating ion exchanger and its applications as an Amphoteric exchanger, Separat. Sci. Technol. 50 (2015) 343-353.

[33] C. Demirbilek, C. Ö. Dinc, Synthesis of diethylaminoethyl dextran hydrogel and its heavy metal ion absorption characteristics. Carbo. Polym. 90 (2012) 1159-1167.

[34] B. Gao, Y. Gao, Y. Li, Preparation and chelation absorption property of composite chelating material poly(amidoxime) $/ \mathrm{SiO}_{2}$ towards heavy metal ions. Chem. Eng. J. 158 (2010) 542-549.

[35] D. William, C. Birkinshaw, T. F. O’Dwyer, Heavy metal adsorbents prepared from the modification of cellulose: A review. Bioresour. Technol. 99 (2008) 6709-6724. 
[36] D. Kołodynska,. Polyacrylate anion exchangers in sorption of heavy metal ions with the biodegradable complexing agent. Chem. Eng. J. 150 (2009) 280-288.

[37] M. Cegłowski, G. Schroeder, Preparation of porous resin with Schiff base chelating groups for removal of heavy metal ions from aqueous solutions. Chem. Eng. J. 263 (2015) 402-411.

[38] L. C. Lin, R. S. Juang, Ion-exchange equilibria of $\mathrm{Cu}(\mathrm{II})$ and $\mathrm{Zn}$ (II) from aqueous solutions with Chelex 100 and Amberlite IRC 748 resins. Chem. Eng. J. 112 (2005) $211-218$.

[39] T. H. Karppinen, A. Y. Pentti, Evaluation of selective ion exchange for nickel and cadmium uptake from the rinse water of a plating shop. Sep. Sci. Technol. 35 (2000) $1619-1633$.

[40] S. W. Ngah, S. Fatinathan, Adsorption characterization of $\mathrm{Pb}(\mathrm{II})$ and $\mathrm{Cu}(\mathrm{II})$ ions onto chitosan-tripolyphosphate beads: Kinetic, equilibrium and thermodynamic studies. J. Environ. Manage. 91 (2010) 958-969.

[41] D. Kołodynska, Polyacrylate anion exchangers in sorption of heavy metal ions with the biodegradable complexing agent. Chem. Eng. J. 150 (2009) 280-288.

[42] A. Gil, S. Albeniz, S. A. Korili, Valorization of the saline slags generated during secondary aluminium melting processes as adsorbents for the removal of heavy metal ions from aqueous solutions. Chem. Eng. J. 251 (2014) 43-50. 
[43] M. Tamutsiwa, D. Chieu, Synergistic adsorption of heavy metal ions and organic pollutants by supramolecular polysaccharide composite materials from cellulose, chitosan and crown ether. J. Hazard. Mater. 264 (2014) 449-459.

[44] C. Srilakshmi, R. Saraf, Ag-doped hydroxyapatite as efficient adsorbent for removal of Congo red dye from aqueous solution: Synthesis, kinetic and equilibrium adsorption isotherm analysis. Microp. Mesop. Mater.219 (2016) 134-144.

[45] W. Dong, Y. Bian, L. Liang, B. Gu, Binding constants of mercury and dissolved organic matter determined by a modified ion exchange technique. Environ. Sci. Technol. 45 (2011) 3576-3583.

[46] G. Bayramoğlu, M. Y. Arıca, Removal of heavy mercury(II), cadmium(II) and zinc(II) metal ions by live and heat inactivated Lentinus edodes pellets. Chem. Eng. J. 143 (2008) 133-140.

[47] F. Fu, Q. Wang, Removal of heavy metal ions from wastewaters: A review. J. Environ. Manage. 92 (2011) 407-418.

[48] W. M. Du, H. Zhu, S. Bao, T. Yang, M. Zou, Structure regulation of silica nanotubes and their adsorption behaviors for heavy metal ions: $\mathrm{pH}$ effect, kinetics, isotherms and mechanism. J. Hazard. Mater. 286 (2015) 533-544. 
[49] L. Zhou, Y. Wang, Z. Liu, Q. Huang, Characteristics of equilibrium, kinetics studies for adsorption of $\mathrm{Hg}^{2+}, \mathrm{Cu}^{2+}$ and $\mathrm{Ni}^{2+}$ ions by thiourea-modified magnetic chitosan microspheres. J. Hazard. Mater. 161 (2009) 995-1002.

[50] Y. Kawamura, H. Yoshida, S. Asai, H. Tanibe, Elution of Hg(II) adsorbed on highly porous polyaminated chitosan beads. J. Chem. Eng. Jpn. 31 (1998) 1-6.

[51] L. Mihaly-Cozmuta, A. Mihaly-Cozmuta, A. Peter, C. Nicula, H. Tutu, D. Silipas, E. Indrea, Adsorption of heavy metal cations by Na-clinoptilolite: Equilibrium and selectivity studies. J. Environ. Manage. 137 (2014) 69-80. 